\title{
Assessing the environmental impact of induction motors using manufacturer's data and life cycle analysis
}

\author{
M. Torrent E. Martinez P. Andrada \\ Departament d'Enginyeria Elèctrica, Universitat Politècnica de Catalunya, Barcelona, Spain \\ E-mail: mtorrent@ee.upc.edu
}

\begin{abstract}
Herein is reported development and testing of a life cycle analysis (LCA) procedure for assessing the environmental impact of induction motors. The operating conditions of a given industrial application are defined by the mechanical power required, operating hours and service life of the three-phase induction motor involved. Based on manufacturer's data mainly, different three-phase induction motors for various sets of operating conditions, including oversizing, have been selected. To quantify the environmental impact of each motor, the Methodology for the Ecodesign of Energy Using Products (MEEUP) was applied, according to the quantity of each of the motor's main constituent materials used in the production phase, and to the two operating variables that directly influence the LCA results: output power and efficiency. The procedure was applied to different three-phase induction motors representing two efficiency categories (IE1 and IE2) and considering different oversizing possibilities. The total environmental impact of each motor was determined based on the production, service life and end-of-life phases. The best motor option was identified for different operating conditions. Given the potential for energy savings in electric motors, LCA-based environmental impact assessment should be performed when different motors are being evaluated for a given industrial application.
\end{abstract}

\section{Introduction}

Three-phase induction motors are the most widely used electric motors in industrial applications, especially in pumps, fans, compressors and conveyors [1]. Although the bulk of work to reduce the environmental impact of induction motors can be done in the design phase [2], consideration of environmental factors when choosing a motor for a specific application can provide significant energy savings over the course of its service life [3].

Specifications for the ecodesign of electric motors have been set in European Commission Regulation EC 640/2009 [4], which mainly is based on studies presented in the report entitled 'EUP Lot 11 Motors' [5]. The regulation indicates the minimum efficiency necessary to meet the specifications for the ecodesign of electric motors (categories IE1: standard efficiency; IE2: high efficiency; and IE3: premium efficiency, as specified in standard IEC60034-30 [6]), in an attempt to harmonise the different efficiency categories for motors having the following characteristics: two, four or six poles; 50 or $60 \mathrm{~Hz}$; rated voltage up to $1000 \mathrm{~V}$; and rated power of $0.75-370 \mathrm{~kW}$ [7]. In this regulation, only the efficiency at full load (FL) is considered. However, in many applications, the motor does not operate at FL. Indeed, motors that drive air fans, heating, ventilation and air-conditioning systems generally operate at $70-75 \%$ of their rated load [8]. The efficiency in oversized motors decreases with diminishing load, especially when operating below $50 \%$ of the rated load.
Efficiency values at different loads are sometimes not included in manufacturer's data, thus complicating assessment of the motor's efficiency in applications that do not require operation at FL [9].

The efficiency categories and the oversized level of induction motors selected in industrial application are the main factors that determine the total environmental impact of electric motors $[10,11]$. To evaluate this environmental impact the methodology for the ecodesign of energy using products [12] has been used. This methodology is based on the use of a spreadsheet in which life cycle analysis (LCA) is applied to a set of data basically comprising the quantity of each material used to manufacture the motor, and the electrical energy that the motor consumes during the service life phase (according to its power and efficiency). In the spreadsheet, the environmental impact ratios outlined in the document MEEUP 2005 are applied [12].

In the case study reported here, different three-phase induction motors (power range: $0.75-370 \mathrm{~kW}$ ) were evaluated using the MEEUP procedure. Efficiencies (for the categories IE1 and IE2) at FL, 75\% rated load and 50\% rated load are included in the manufacturers' data. Diverse values for required output power, operating hours and service life were studied, considering that the motors operate continuously at a given power level (over the time of operation). The best motor option (i.e. with the lowest environmental impact) was determined for each set of operating conditions. 


\section{Calculation procedure}

This section describes the calculation procedure developed to determine the total environmental impact of each motor option studied, considering different operating conditions (Fig. 1).

\subsection{Operating conditions definition}

For the different operating conditions studied, the mechanical power requirements of the industrial application must be defined. For the case study, a mechanical power coincident with the output rated power in the manufacturer's data lists $(0.75-370 \mathrm{~kW})$ was considered.

Values for the annual operating hours (h/year) and the service life (years) must be set for the industrial application: the recommended values for a base case are $4000 \mathrm{~h} /$ year and 12 years [5], respectively, but for the case reported here, different values were considered: $1000-8000 \mathrm{~h} /$ year and $10-20$ years, respectively.

\subsection{Manufacturer's data selection}

In the manufacturer's data selected ( $50 \mathrm{~Hz}$ four-pole motors), the efficiencies of each motor at FL, 75\% rated load and 50\% rated load are known for the IE1 and IE2 efficiency categories (Fig. 2).

\subsection{Bill of materials}

The quantities of materials used for manufacturing the motor are needed to calculate the motor's environmental impact during the production phase. The bill of materials used is calculated from the average values indicated in 'EUP Lot 11 Motors' (Table 1). The bill of materials values for each motor were compiled based on the values indicated in Table 1 and the average values have been calculated to other power ranges.

\subsection{Operating variables}

In order to quantitatively evaluate the different oversizing levels, the motor load index is introduced as

$$
\text { Motor load index }=\frac{P_{\text {mechanical power requirement }}}{\text { Rated power motor selected }}
$$

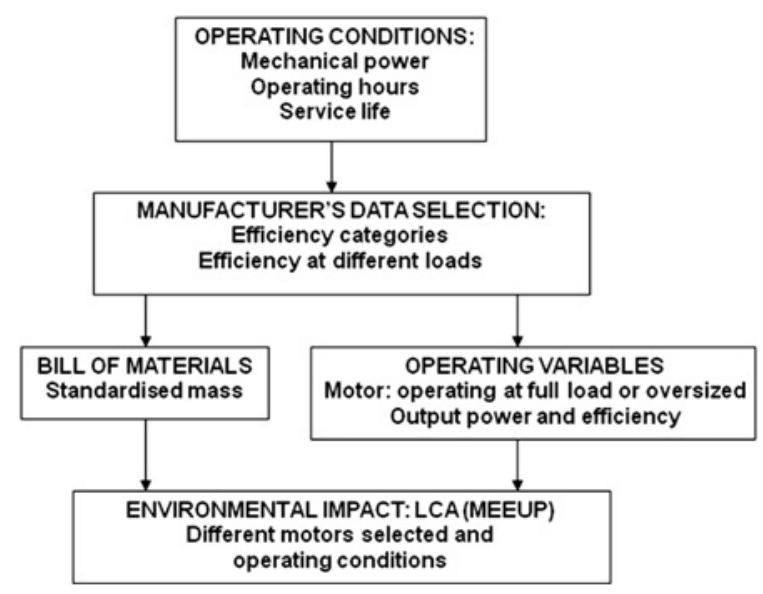

Fig. 1 Calculation procedure developed
The motor load index is easily calculated from the manufacture's data and for each studied mechanical power requirements, three motor operation alternatives are considered:

- FL: the rated power of the motor selected is coincident with the mechanical power requirement.

- Moderately oversized (MO): the rated power of the motor selected is one level higher than that indicated in the manufacturer's data list.

- Significantly oversized (SO): the rated power of the motor selected is two levels higher than that indicated in the manufacturer's data list.

Two motor efficiency categories are considered:

- IE1: standard efficiency.

- IE2: high efficiency.

The values of the motor load index for the mechanical power requirement obtained when the motor selected is oversized are shown in Fig. 3. If the motor load index obtained in each studied case from (1) is not coincident with these manufacturer's data values, then a linear interpolation is used to calculate the efficiency at this operation point.

\subsection{LCA and environmental impact}

The MEEUP methodology is a useful tool for LCA. This methodology is based on European regulations and is designed for assessment of the environmental impact of energy-consuming products in function of their production, distribution, service life and waste recycling and disposal. The methodology should follow - but not replace - current environmental guidelines established in international treaties and enacted in appropriate EU legislation. The tools for assessing the environmental impact are based on accepted scientific principles and the data were collected from industry associations, EC reports and environmental studies from companies. The MEEUP methodology [11] is a simple method implemented in a spreadsheet. Energy-using products or parts are the subject of the MEEUP methodology application: energy industry, industrial machinery, textiles, beverages, furniture, services etc. It also makes them very special from a methodological point of view because they are by definition products actively consuming energy resources during product life. The main two parts of MEEUP methodology are:

- Inputs (bill of materials; performance, consumption and emission characteristics during the service life phase; volume of final product packaging; waste recycling and disposal).

- Results, which are presented as a list of environmental indicators (total energy, water, waste, global warming potential, acidification emissions, heavy metals, particulate matter, eutrophication etc.).

The MEEUP methodology was applied to determine the environmental impact of each of the motors selected at each level of mechanical power requirement (IE1 FL, IE1 MO, IE1 SO, IE2 FL, IE2 MO, IE2 SO) in the different operating conditions studied (mechanical power requirement: $0.75-375 \mathrm{~kW}$; operating hours: $1000-$ 8000 h/year; service life phase: $10-20$ years). To compare 

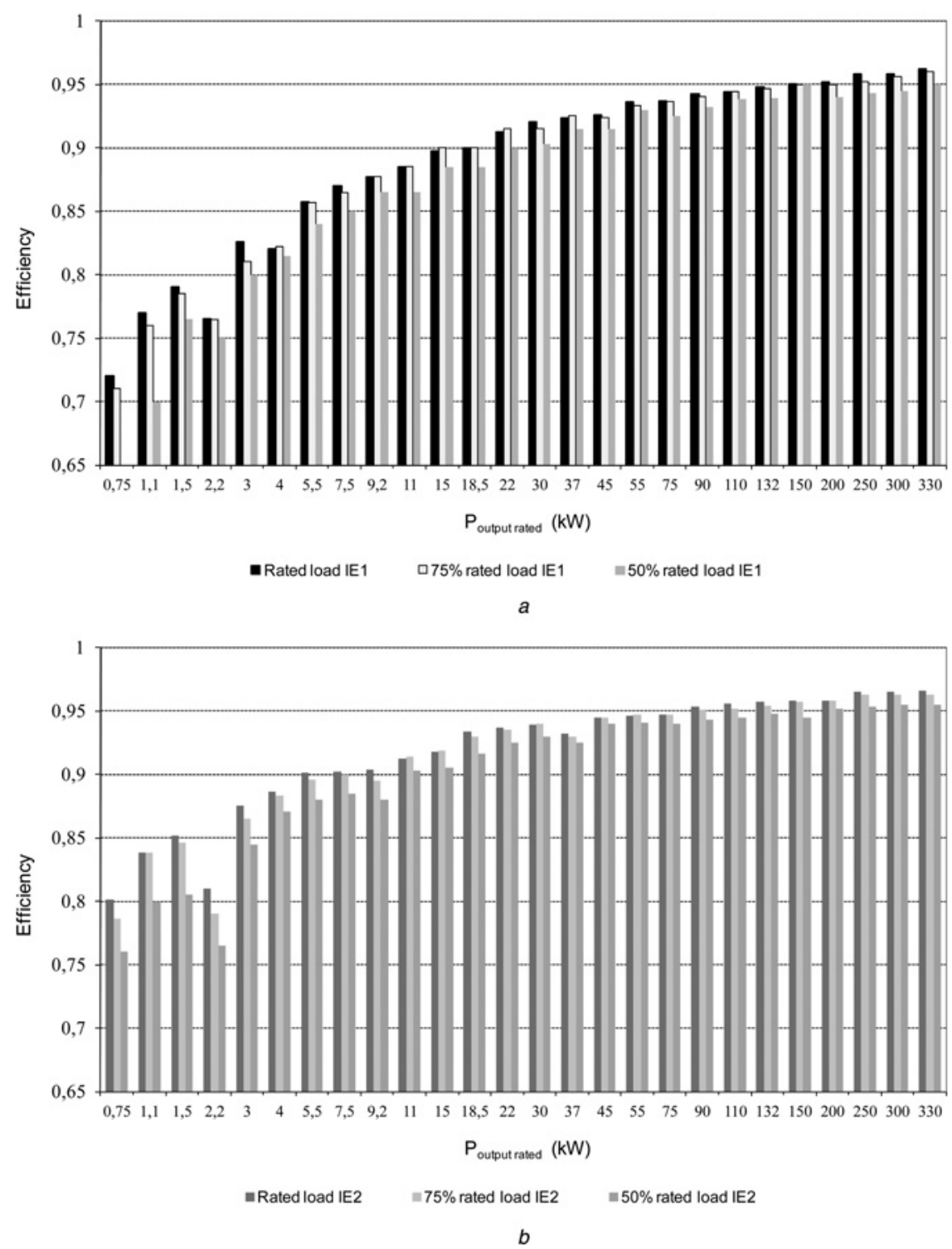

Fig. 2 Efficiencies in the manufacturer data of the selected motors (50 Hz, four poles)

$a$ Motors with efficiency IE1

$b$ Motors with efficiency IE2

Table 1 Bill of materials for the IE1 and IE2 motors (average values)

\begin{tabular}{|c|c|c|c|c|c|c|}
\hline & \multicolumn{3}{|c|}{ IE1 } & \multicolumn{3}{|c|}{ IE2 } \\
\hline & $1.1 \mathrm{~kW}$ & $11 \mathrm{~kW}$ & $110 \mathrm{~kW}$ & $1.1 \mathrm{~kW}$ & $11 \mathrm{~kW}$ & $110 \mathrm{~kW}$ \\
\hline electrical steel, $\mathrm{kg} / \mathrm{kW}$ & 5.4 & 3.6 & 3.1 & 8 & 4.8 & 3.6 \\
\hline other steel, kg/kW & 1.5 & 0.95 & 0.67 & 1.6 & 1 & 0.7 \\
\hline cast iron, $\mathrm{kg} / \mathrm{kW}$ & 2.5 & 1.3 & 3 & 2.5 & 1 & 3 \\
\hline aluminum, kg/kW & 1.7 & 0.9 & 0.18 & 0.45 & 1.1 & 0.2 \\
\hline copper, kg/kW & 1.24 & 0.64 & 0.54 & 1.9 & 0.9 & 0.6 \\
\hline
\end{tabular}

Following equivalences in the efficiency categories were considered: IE $1 \equiv \mathrm{Eff} 2$, IE2 $\equiv \mathrm{Eff} 1$

the environmental impact obtained for each motor, the results obtained at IE1 FL were used as the reference values (assigned a value of 1.0); the other results were normalised to this value. To quantify the total environmental impact ratio, environmental impacts per individual category were first calculated for each of the existing environmental indicators in MEEUP. The results for each indicator were compared to the results obtained in the option IE1 FL, using the relative environmental indicator (i) given by

Relative environmental indicator $(i)$

$$
=\frac{\text { Total environmental impact }(i)}{\text { Total environmental impact }(i) \text { at IE1 Full load }}
$$




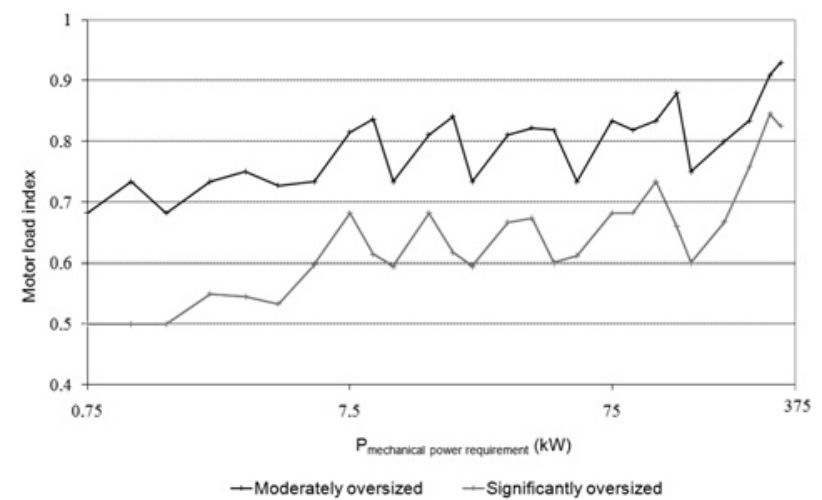

Fig. 3 Mechanical power requirements plotted against motor load index for oversized motors

The environmental impact ratio (total) was then estimated from the average of the different relative environmental indicators in MEEUP, using (3), where in a first approach we have considered the same relative weight for each indicator used

$$
\begin{aligned}
& \text { Environmental impact ratio (total) } \\
& =\frac{\sum_{i=1}^{i=n} \text { Relative environmental indicators }(i)}{n}
\end{aligned}
$$

\section{Results and discussion}

\subsection{Case of study}

As a representative example, the results of the environmental impact obtained for the $22 \mathrm{~kW}$ mechanical power requirements are shown in Tables 2 and 3. The results correspond to the following operating conditions:

- Mechanical power requirements: $22 \mathrm{~kW}$ (50 Hz, four-pole motor).

- Operating hours: $4000 \mathrm{~h} /$ year.

- Service life: 12 years.

- The following options for motor rated power were considered:

- FL: $22 \mathrm{~kW}$ (motor load index =1).

- MO: $30 \mathrm{~kW}$ (motor load index $=0.73$ ).

- SO: $37 \mathrm{~kW}$ (motor load index $=0.59$ ).

Among the environmental indicators (results of MEEUP methodology), have been selected the following:

- Total energy (GER): primary energy used in the various stages of the product life.

- Water (process): water from the public grid that is used in a process and is then usually disposed off through the sewage system or as water vapour to air.

\begin{tabular}{|c|c|c|c|c|c|c|c|}
\hline & Unit & IE1 FL & IE1 MO & IE1 SO & IE2 FL & IE2 MO & IE2 SO \\
\hline \multicolumn{8}{|l|}{ Resources and waste } \\
\hline total energy (GER) & MJ & 1077343 & 1050329 & 991714 & 754524 & 727765 & 888417 \\
\hline water (process) & 1 & 71338 & 69391 & 65361 & 49716 & 47760 & 58327 \\
\hline $\begin{array}{l}\text { waste, non-haz./landfill } \\
\text { Emissions (air) }\end{array}$ & g & 1719460 & 1831108 & 1883796 & 1470521 & 1608095 & 1934705 \\
\hline Greenhouse gases in GWP100 & $\mathrm{kg} \mathrm{CO} 2$ eq. & 47186 & 46060 & 43548 & 33136 & 32031 & 39095 \\
\hline acidification, emissions & $\mathrm{g} \mathrm{SO}_{2}$ eq. & 281382 & 275607 & 261506 & 199380 & 193875 & 236389 \\
\hline heavy metals & mg Ni eq. & 20081 & 20114 & 19528 & 14994 & 15124 & 18372 \\
\hline $\begin{array}{l}\text { particulate matter (PM, dust) } \\
\text { Emissions (water) }\end{array}$ & g & 6280 & 6236 & 6002 & 4567 & 4543 & 5531 \\
\hline eutrophication & $\mathrm{g} \mathrm{PO}_{4}$ & 41.9 & 43.9 & 44.4 & 34.4 & 36.8 & 44.5 \\
\hline
\end{tabular}

Table 2 Total environmental impact values of each of the six motor options

Mechanical power requirement: $22 \mathrm{~kW}$; operating hours: 4000 h/year; service life span: 12 years

\begin{tabular}{|c|c|c|c|c|c|c|}
\hline & IE1 FL & IE1 MO & IE1 So & IE2 FL & IE2 MO & IE2 SO \\
\hline \multicolumn{7}{|l|}{ Resources and waste } \\
\hline total energy (GER) & 1 & 0.9749 & 0.9205 & 0.7003 & 0.6755 & 0.8246 \\
\hline water (process) & 1 & 0.9727 & 0.9162 & 0.6969 & 0.6695 & 0.8176 \\
\hline waste, non-haz./landfill & 1 & 1.0649 & 1.0955 & 0.8552 & 0.9352 & 1.1252 \\
\hline \multicolumn{7}{|l|}{ Emissions (air) } \\
\hline Greenhouse gases in GWP100 & 1 & 0.9761 & 0.9229 & 0.7022 & 0.6788 & 0.8285 \\
\hline acidification, emissions & 1 & 0.9794 & 0.9293 & 0.7085 & 0.6891 & 0.8401 \\
\hline heavy metals & 1 & 1.0016 & 0.9724 & 0.7466 & 0.7531 & 0.9148 \\
\hline particulate matter (PM, dust) & 1 & 0.9931 & 0.9558 & 0.7273 & 0.72347 & 0.8808 \\
\hline \multicolumn{7}{|l|}{ Emissions (water) } \\
\hline eutrophication & 1 & 1.0460 & 1.0589 & 0.8189 & 0.8775 & 1.0608 \\
\hline environmental impact ratio (total) & 1 & 1.0011 & 0.9715 & 0.7445 & 0.7503 & 0.9116 \\
\hline
\end{tabular}

Table 3 Relative environmental indicators and total environmental impact ratio of each of the six motor options

Mechanical power requirement: 22 kW; operating hours: 4000 h/year; service life span: 12 years. Reference value: IE1 motor at full load (1.0) 


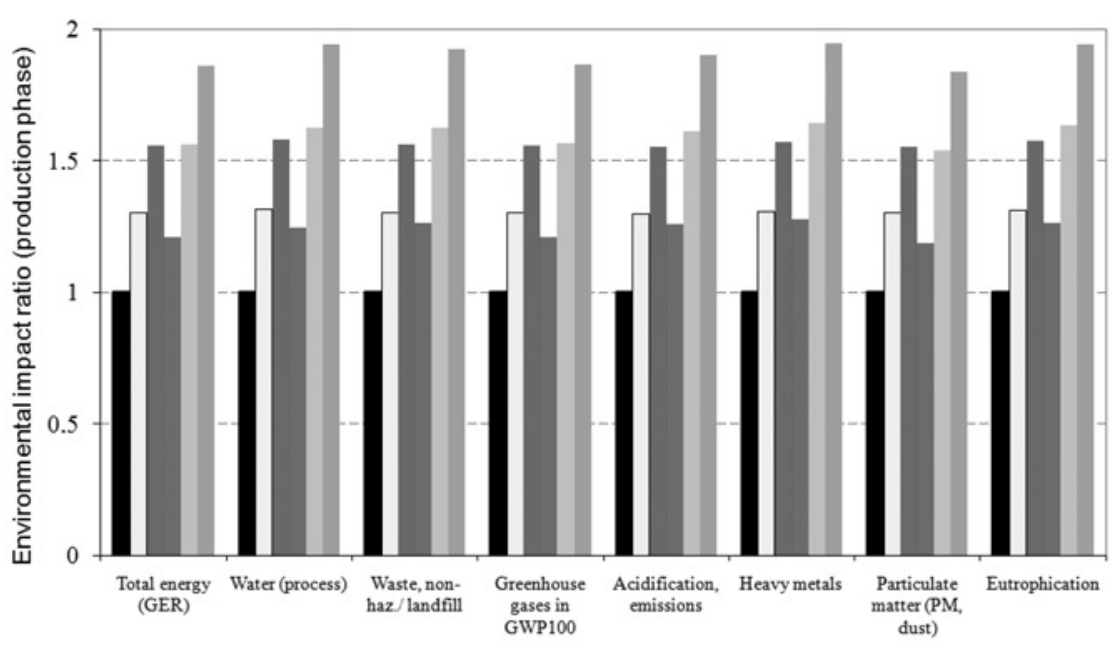

-IE1FL DIE1MO $=I E 1 S O=I E 2 F L=I E 2 M O=I E 2 S O$
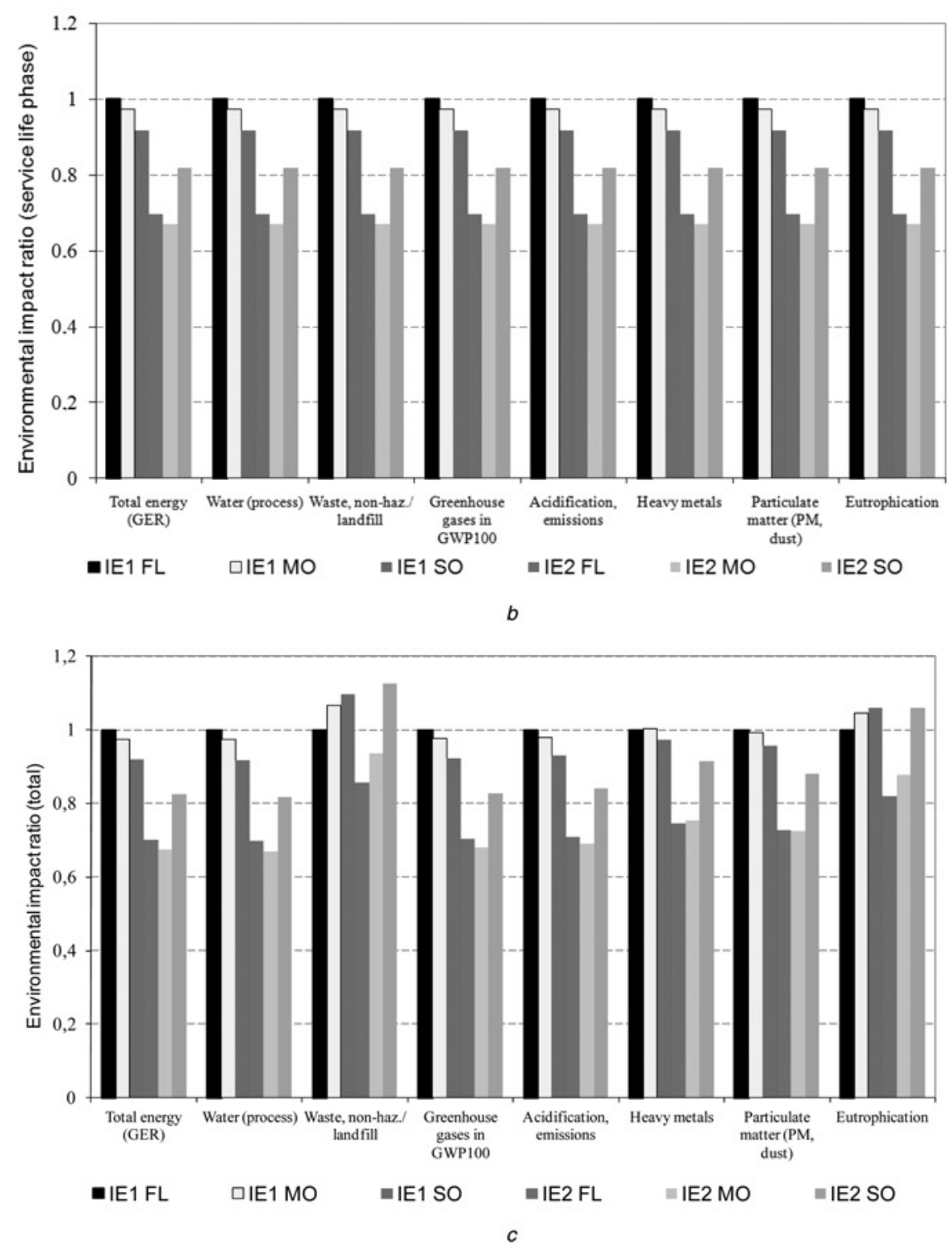

Fig. 4 Comparison of the environmental impact of each of the six motors in the production phase, service life phase and total Mechanical power requirement: $22 \mathrm{~kW}$; operating hours: 4000 h/year; service life span: 12 years. Reference value: IE1 motor at FL (1.0) a Production phase

$b$ Service life phase

c Total 
- Waste, non-haz./landfill: quantities of waste nonhazardous split between landfill and incinerated (without heat recovery).

- Greenhouse gases in GWP100: global warming potential using weighting factors from IPCC 2001 (Intergovernmental Panel on Climate Change).

- Acidification, emissions: $\mathrm{SO}_{x}, \mathrm{NO}_{x}$ and ammonia emissions.

- Heavy metals: relates to emissions of regulated heavy metal, weighted according to their emission limit values as specified in current legislation of air quality.

- Particulate matter (PM, dust): indicator for smog and ground level ozone.

- Eutrophication: refer to substances that influence the oxygen balance of the water.

The environmental impact of each of the six motor options in the production phase, in the service life phase and in total are compared in Fig. 4 [13].
The total environmental impact ratio at 4000 operating hours/year and a service life of 12 years were calculated using the same procedure for all the mechanical power requirements studied in a power range of $0.75-370 \mathrm{~kW}$. The results are shown in Fig. 5. The operational energy component is the highest component of the total environmental impact. This effect is observed in Fig. 6.

As observed in Fig. 5, at nearly all the mechanical power values studied, the total environmental impact of IE2 motors is less than the total environmental impact of IE1 motors, even when the former are oversized. The power values of $1.1,1.5$ and $300 \mathrm{~kW}$ are an exception to this trend, in which one of the oversized IE2 motors exhibits a higher impact ratio than any of the IE1 motors. These results can be explained by the fact that the service life phase has a greater impact than does the production phase: using a more-efficient motor - even one that implies higher materials demands for manufacturing - provides a lower total impact.
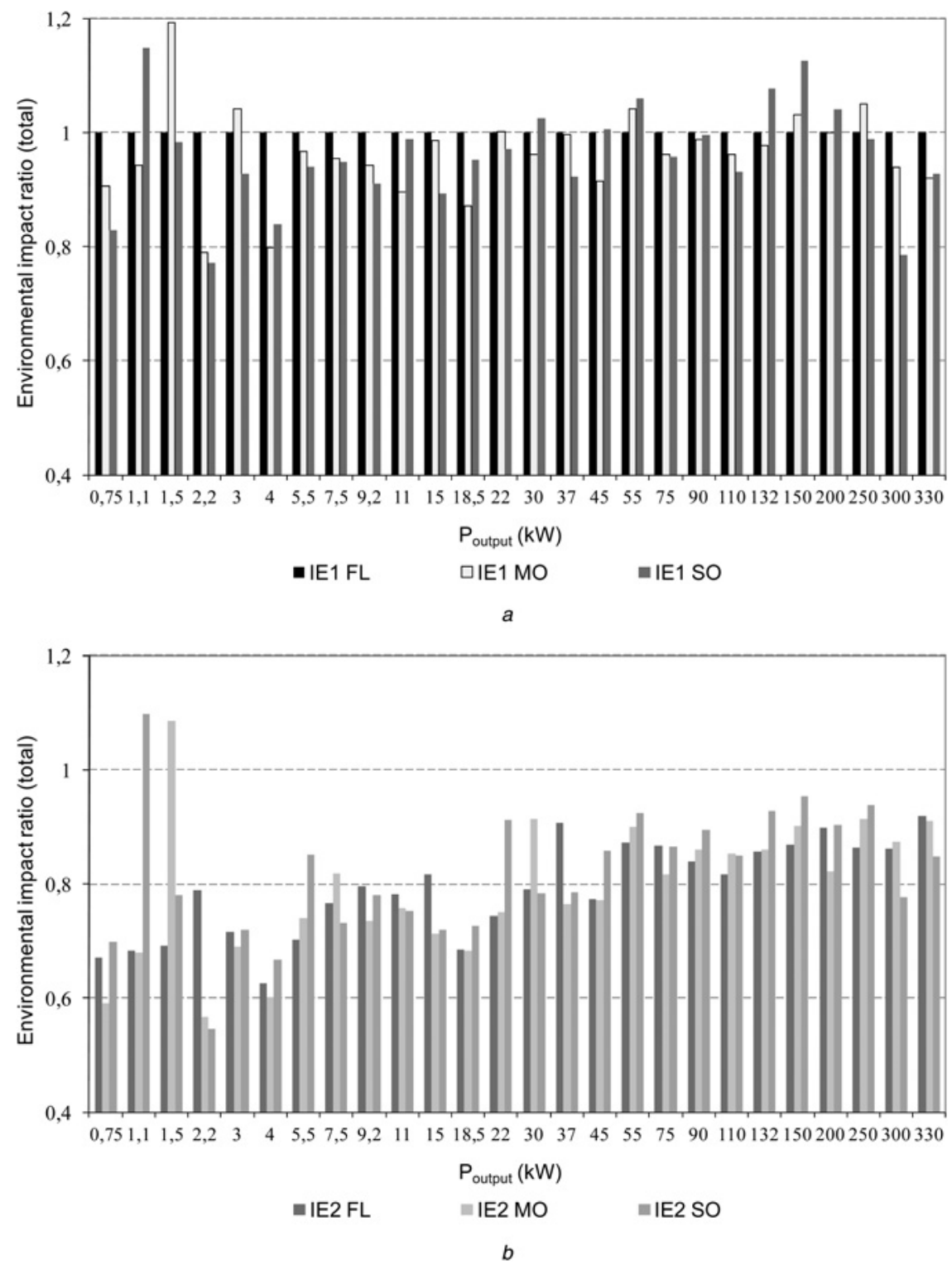

Fig. 5 Total environmental impact ratio of each of the six motors at each mechanical power requirement value studied Operating hours: $4000 \mathrm{~h} /$ year; service life span: 12 years. Reference value: IE1 motor at FL (1.0)

$a$ Motors with efficiency IE1

$b$ Motors with efficiency IE2 

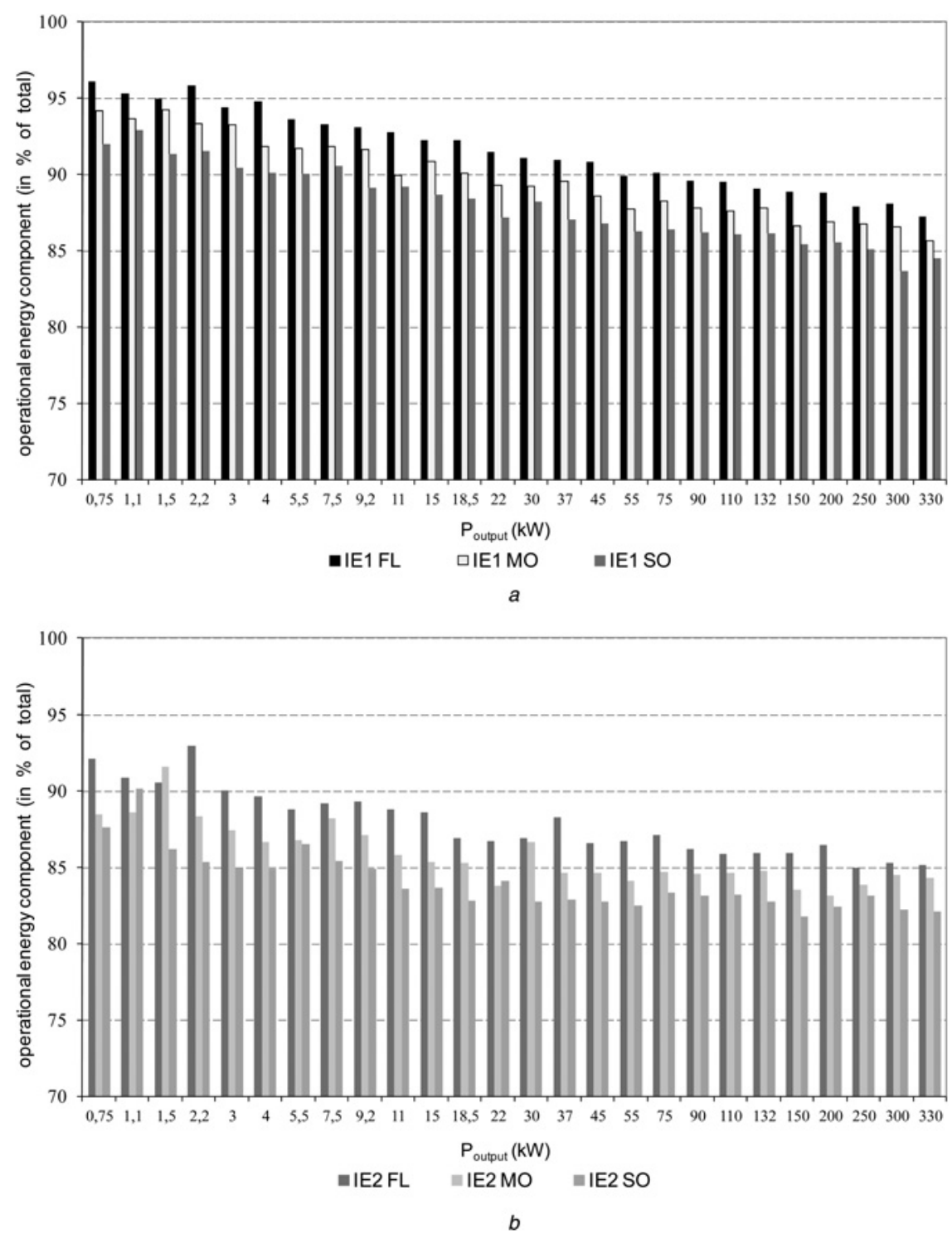

Fig. 6 Operational energy component (in \%) of the total environmental impact

Operating hours: $4000 \mathrm{~h} /$ year; service life span: 12 years

$a$ Motors with efficiency IE1

$b$ Motors with efficiency IE2

Comparison of the IE2 motor options reveals that none of them is clearly superior. Thus, the following combinations offer the lowest impact:

- FL at power requirements of $1.5,5.5,22,55,90,110,132$, 150 and $250 \mathrm{~kW}$;

- $\mathrm{MO}$ at $0.75,1.1,3,4,9.2,15,18.5,37,45,75$ and $200 \mathrm{~kW}$;

- $\mathrm{SO}$ at $2.2,7.5,11,30,300$ and $330 \mathrm{~kW}$.

Comparison of the IE1 motor options reveals that SO provides the lowest total environmental impact in most cases: at $0.75,1.5,2.2,3,5.5,7.5,9.2,15,22,37,75,110$, 250 and $300 \mathrm{~kW}$. For the remaining cases, the following combinations offer the lowest impact:

- FL at power requirements of 55, 150 and $200 \mathrm{~kW}$;

- $\mathrm{MO}$ at 1.1, 4, 11, 18.5, 30, 45, 90, 132 and $330 \mathrm{~kW}$.

To facilitate decision making, the best and worst choice for each mechanical power requirement and the conditions studied (at an operating $4000 \mathrm{~h} /$ year and life 12 years) are listed in Table 4. Obviously, scenarios involving different values for operating hours or service life would imply different values for environmental impact. For example, Figs. 7 and 8 show, for the mechanical power requirement of $22 \mathrm{~kW}$, the variation in environmental impact at different operating conditions. Analysis of the results reveals that the reference values only become unreliable at very high or low values for operating hours $(<2000 \mathrm{~h}$ or $>6000 \mathrm{~h} /$ year $)$ or service life $(<10$ or $>20$ years). In Table 4 , the changes in the trend observed with the calculation procedure are indicated in the additional columns.

Table 4 clearly shows that among the analysed motors, an IE2 motor FL or MO offers the lowest environmental impact according to the required mechanical power. The least oversized options exhibit the lowest environmental impact in applications that require less operating hours, and in some cases, oversized motors may prove to be interesting for applications that demand a high number of operating hours $(>6000 \mathrm{~h} /$ year $)$. 
Table 4 Environmental impact of the motor options studied

\begin{tabular}{|c|c|c|c|c|c|c|}
\hline \multirow{2}{*}{$\begin{array}{l}\text { Mechanical power } \\
\text { requirements }(\mathrm{kW})\end{array}$} & \multicolumn{3}{|c|}{ Best option (lowest environmental impact) } & \multicolumn{3}{|c|}{ Worst option (highest environmental impact) } \\
\hline & $\begin{array}{c}<2000 \mathrm{~h} / \text { year or } \\
<10 \text { years }\end{array}$ & $\begin{array}{c}4000 \mathrm{~h} / \text { year and } \\
12 \text { years }\end{array}$ & $\begin{array}{l}>6000 \text { hours/year } \\
\text { or }>20 \text { years }\end{array}$ & $\begin{array}{c}<2000 \mathrm{~h} / \text { year or } \\
<10 \text { years }\end{array}$ & $\begin{array}{c}4000 \mathrm{~h} / \text { year and } \\
12 \text { years }\end{array}$ & $\begin{array}{c}>6000 \mathrm{~h} / \text { year or } \\
>20 \text { years }\end{array}$ \\
\hline 0.75 & IE2 FL & IE2 MO & & & IE1 FL & \\
\hline 1.1 & & IE2 MO & & IE2 SO & IE1 SO & \\
\hline 1.5 & & IE2 FL & & & IE1 MO & \\
\hline 2.2 & IE2 MO & IE2 SO & & & IE1 FL & \\
\hline 3 & IE2 FL & IE2 MO & & & IE1 MO & \\
\hline 4 & & IE2 MO & & & IE1 FL & \\
\hline 5.5 & & IE2 FL & & IE1 So & IE1 FL & \\
\hline 7.5 & IE2 FL & IE2 SO & & IE1 So & IE1 FL & \\
\hline 9.2 & & IE2 MO & & IE1 So & IE1 FL & \\
\hline 11 & IE2 FL & IE2 SO & & IE1 So & IE1 FL & \\
\hline 15 & & IE2 MO & IE2 SO & IE1 MO & IE1 FL & \\
\hline 18.5 & & IE2 MO & & IE1 SO & $\mathrm{IE} 1 \mathrm{FL}$ & \\
\hline 22 & & IE2 FL & IE2 MO & & IE1 MO & \\
\hline 30 & IE2 MO & IE2 SO & & & IE1 SO & \\
\hline 37 & & IE2 MO & & IE1 MO & $\mathrm{IE} 1 \mathrm{FL}$ & \\
\hline 45 & IE2 FL & IE2 MO & & & IE1 SO & IE1 FL \\
\hline 55 & & IE2 FL & & & IE1 So & \\
\hline 75 & & IE2 MO & & IE1 SO & $\mathrm{IE} 1 \mathrm{FL}$ & \\
\hline 90 & & IE2 FL & & IE1 SO & IE1 FL & \\
\hline 110 & & IE2 FL & & IE1 SO & $\mathrm{IE} 1 \mathrm{FL}$ & \\
\hline 132 & & $\mathrm{IE} 2 \mathrm{FL}$ & IE2 MO & & IE1 So & \\
\hline 150 & & IE2 FL & & & IE1 SO & \\
\hline 200 & & IE2 MO & & & IE1 So & \\
\hline 250 & & IE2 FL & & & IE1 MO & \\
\hline 300 & IE1 SO & IE2 SO & & & $\mathrm{IE} 1 \mathrm{FL}$ & \\
\hline 330 & & IE2 SO & & & IE1 FL & \\
\hline
\end{tabular}

Best and worst option is listed for each mechanical power requirement and under the conditions studied (operating hours: $4000 \mathrm{~h} / \mathrm{year}$; service life: 12 years). Deviations from the reference values are indicated in the additional columns

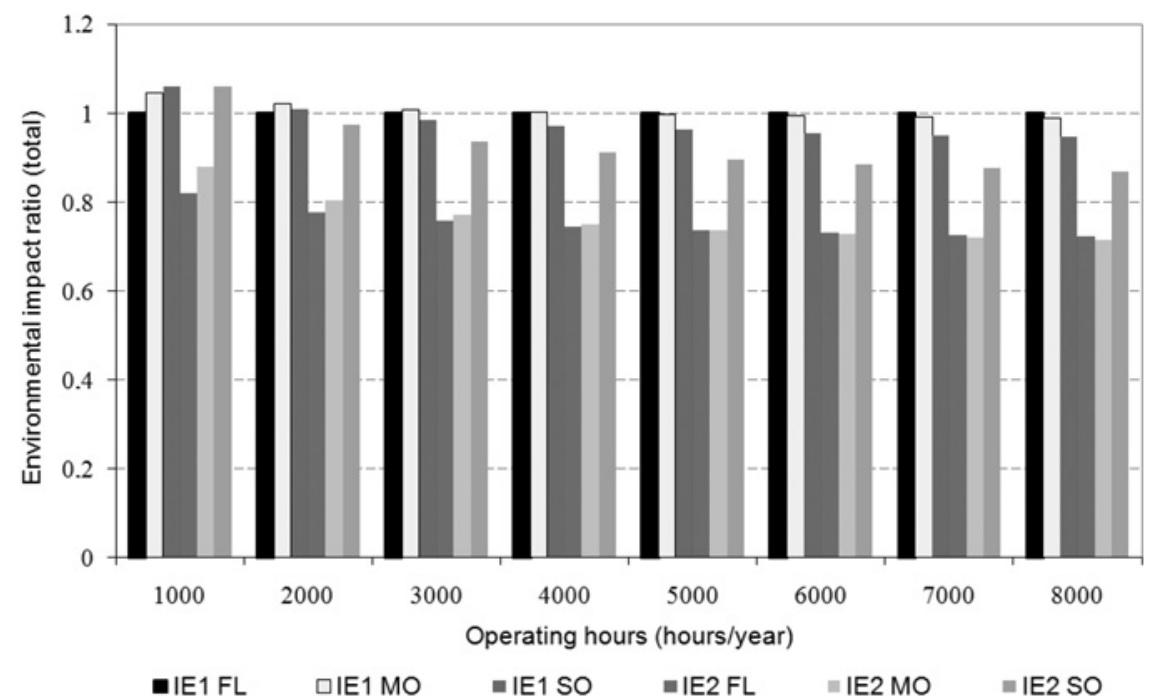

Fig. 7 Total environmental impact ratio of each of the motor options studied in function of annual operating hours Mechanical power requirement: $22 \mathrm{~kW}$; service life: 12 years. Reference value: IE1 motor at FL (1.0)

\subsection{Influence of the weight of different relative environmental indicators in the total environmental impact}

It may be of interest to study the influence on the outcome of the total environmental impact, bearing in mind different weights for the relative environmental indicators considered. In this sense, in the motor of $22 \mathrm{~kW}$, five different cases have been evaluated in which it have been assigned different weights to the relative environmental indicators.

The results are shown in Table 5 (in all new cases, the weight assigned at Greenhouse gases in GWP100 is higher 


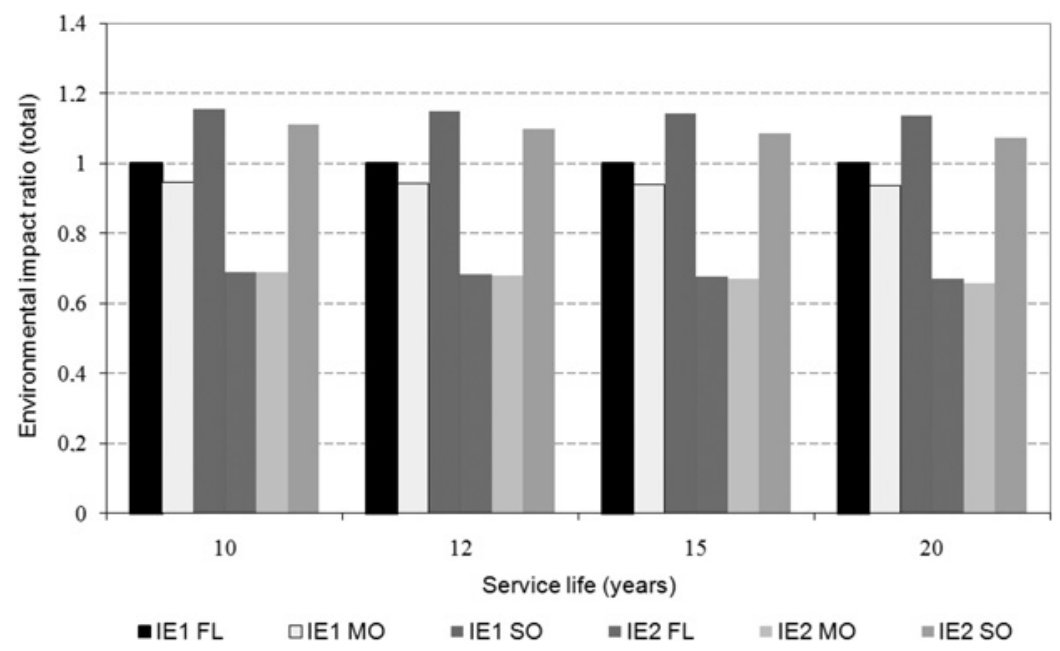

Fig. 8 Total environmental impact ratio of each of the motor options studied in function of service life length Mechanical power requirement: $22 \mathrm{~kW}$; operating hours: $4000 \mathrm{~h} /$ year. Reference value: IE1 motor at FL (1.0)

Table 5 Total environmental impact ratio of each of the six motor options considering different weights of the different environmental indicators

\begin{tabular}{|c|c|c|c|c|c|c|}
\hline & Case 1 & Case 2 & Case 3 & \multicolumn{2}{|c|}{ Case 4} & Case 5 \\
\hline \multicolumn{7}{|c|}{ a) Weights used in the five cases considered } \\
\hline \multicolumn{7}{|l|}{ Resources and waste } \\
\hline total energy (GER) & 0.125 & 0.15 & 0.15 & 0.14 & & 0.13 \\
\hline water (process) & 0.125 & 0.15 & 0.15 & 0.14 & & 0.13 \\
\hline waste, non-haz./ landfill & 0.125 & 0.09 & 0.08 & 0.07 & & 0.07 \\
\hline \multicolumn{7}{|l|}{ Emissions (air) } \\
\hline Greenhouse gases in GWP100 & 0.125 & 0.2 & 0.25 & 0.3 & & 0.35 \\
\hline acidification, emissions & 0.125 & 0.13 & 0.12 & 0.11 & & 0.1 \\
\hline heavy metals & 0.125 & 0.1 & 0.09 & 0.09 & & 0.08 \\
\hline particulate matter (PM, dust) & 0.125 & 0.1 & 0.09 & 0.09 & & 0.08 \\
\hline \multicolumn{7}{|l|}{ Emissions (water) } \\
\hline eutrophication & 0.125 & 0.08 & 0.07 & 0.06 & & 0.06 \\
\hline \multicolumn{7}{|c|}{ b) Total environmental impact ratio obtained in the five cases considered } \\
\hline & IE1 FL & IE1 MO & IE1 SO & IE2 FL & IE2 MO & IE2 SO \\
\hline case 1 & 1 & 1.0011 & 0.9715 & 0.7445 & 0.7503 & 0.9116 \\
\hline case 2 & 1 & 0.9937 & 0.9570 & 0.6270 & 0.6278 & 0.7633 \\
\hline case 3 & 1 & 0.9917 & 0.9531 & 0.6235 & 0.6220 & 0.7565 \\
\hline case 4 & 1 & 0.9901 & 0.9501 & 0.6278 & 0.6242 & 0.7595 \\
\hline case 5 & 1 & 0.9897 & 0.9492 & 0.6342 & 0.6298 & 0.7663 \\
\hline
\end{tabular}

Mechanical power requirement: 22 kW; operating hours: 4000 h/year; service life span: 12 years. Reference value: IE1 motor at full load (1.0)

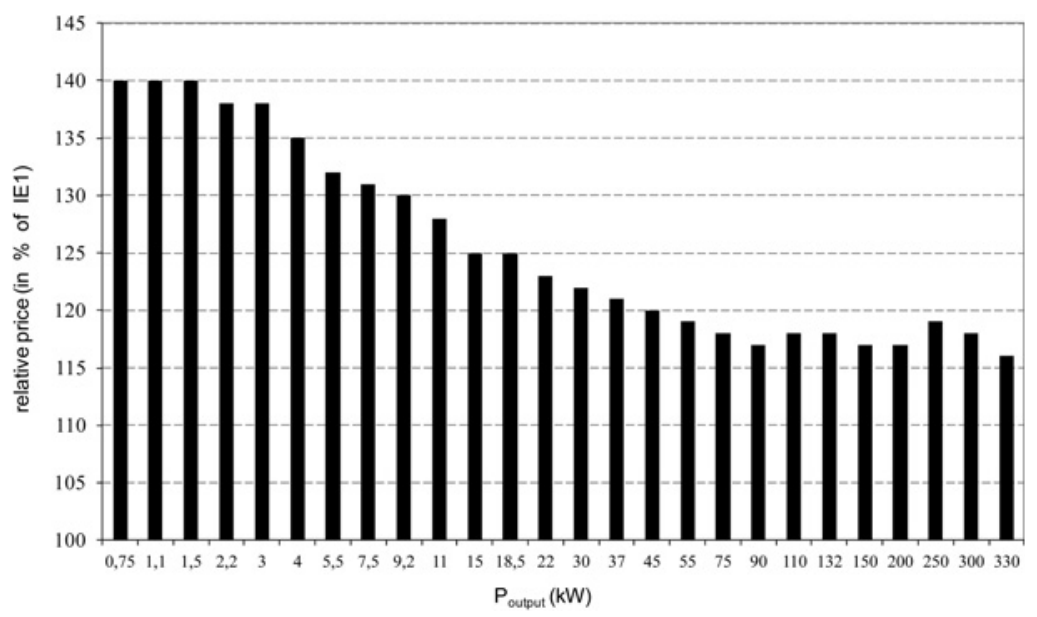

Fig. 9 Relative prices of electric motors with IE2 efficiency respect to electric motors with IE1 efficiency 

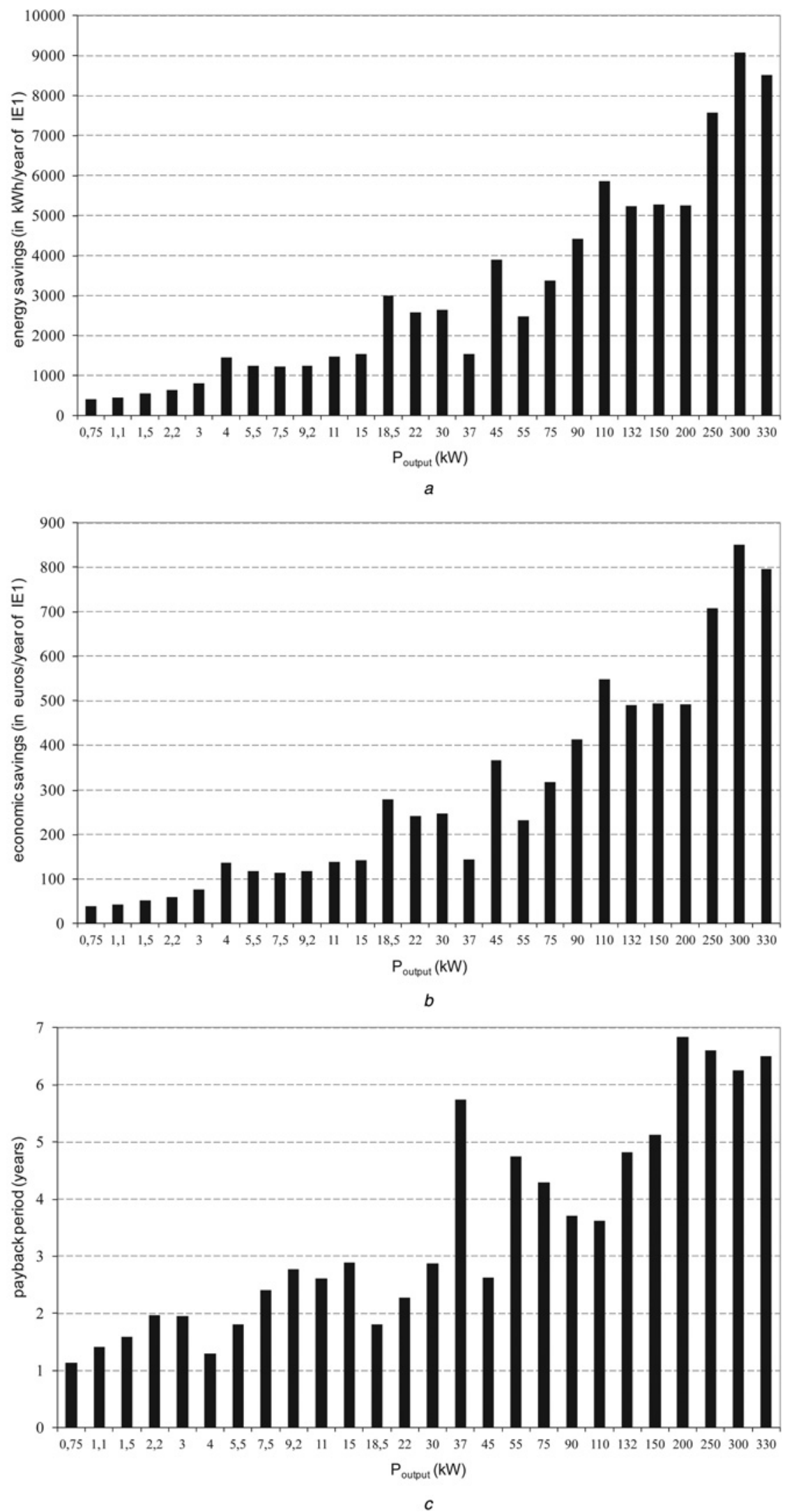

Fig. 10 Energy savings, economic savings associated with the energy savings and payback period related to the selection of an IE2 motor instead of an IE1 motor

Operating hours: $4000 \mathrm{~h}$ /year at FL and service life: 12 years

$a$ Energy savings

$b$ Economic savings associated with the energy savings

c Payback period 
than the others, because certainly, it is, in our view, the most important environmental impact indicator). Although the weight of the different relative environmental impacts in each case studied, it has been changed this has not been translated into significant variations in the selection procedure.

\subsection{Energy savings and costs}

An economic assessment study related to the selection of a motor IE2 instead of an IE1 motor has been carried out for the power range studied and for the standard operation values (operating hours: $4000 \mathrm{~h} /$ year at FL and service life: 12 years). In the study of the life cycle costs, the additional investment that represents the acquisition of IE2 motor has been obtained from [14], and to evaluate the economic savings associated from the energy savings has been used the average electricity prices for industrial consumers in the European Union [15]. Equation (4) is used to calculate the annual energy savings and (5) to calculate the payback period. The results obtained are shown in Figs. 9 and 10:

Annual energy savings (€)

$$
=P \times h \times L \times c \times\left(\frac{1}{\eta_{I E 1}}-\frac{1}{\eta_{I E 2}}\right)
$$

Payback period (years)

$$
=\frac{\text { Price IE2 motor }(€)-\text { Price IE1 motor }(€)}{\text { Annual energy savings }(€ / \text { year })}
$$

where $\mathrm{P}=$ output rated power of the motor $(\mathrm{kW})$, $\mathrm{h}=$ operating time per year (hours) $\mathrm{L}=$ motor load index, $c=$ electricity cost $(€ / \mathrm{kWh}), \quad \eta_{\mathrm{IE} 1}=$ efficiency of IE1 motor at load index considered, $\eta_{\text {IE2 }}=$ efficiency of IE2 motor at load index considered.

\section{Conclusions}

The diversity of available three-phase induction motors of different efficiency categories, and the common practice of oversizing electric motors, generate numerous motor options for any given industrial application. Although environmental impact can be incorporated in the motor design stage, it should also serve as a parameter for choosing among various motors (based on the manufacturer's data) for a given industrial application. Assessing environmental impact in three-phase induction motors is particularly relevant, given the widespread use of these motors in industrial applications and the possibilities for energy savings.
The MEEUP methodology is valuable for quantifying the environmental impact of an electric motor in the production and service life phases, enabling facile comparison of different motors.

The number of operating hours for the motor is a critical factor in determining environmental impact. For most of the operating conditions studied here, the motor options offering the lowest environmental impact are those from the higher-efficiency category (IE2) - namely, when operating at FL or when MO. Nonetheless, every application will ultimately require its own LCA.

\section{References}

1 Pyrhönen, J., Haataja, J., Luostarinen, K., Härkönen, H.: 'High efficient induction motors', weSRCH Green Tech, 13 April 2011

2 Torrent, M., Martínez, E., Andrada, P.: 'Life cycle analysis on the design of induction motors', Int. J. Life Cycle Assess., 2011, 16, (11), pp. 1-8. doi: 10.1007/S11367-011-0332-4

3 Saidur, R.: 'A review on electrical motors energy use and energy savings', Renew. Sustain. Energy Rev., 2010, 14, pp. 877-898

4 European Commission Regulation 640/2009 implementing Directive 2005/32/EC of the European Parliament and of the Council with regard to ecodesign requirements for electric motors, 2009. http:// eur-lex.europa.eu/LexUriServ/LexUriserv.do?uri=OJ:L:2009:191:0026: 0034:EN:PDF

5 De Almeida A.T., Ferreira F.J.T.E., Fong J.A.C., Fonseca P.: EUP Lot 11 Motors: Final. www.ebpg.bam.de/de/ebpg_medien/011_studyf_0804_motots_updated.pdf

6 IEC 60034-30: Rotating electrical machines - Part 30: efficiency classes of single-speed three-phase cage induction motors, 2007

7 Nadel, S., Elliott, R.N., Shepard, M., Greenberg, S., Katz, G., de Almeida, A.T.: 'Energy efficient motor systems: a handbook on technology, program, and policy opportunities' (American Council for an Energy-Efficient Economy, Washington, DC, 2002, 2nd edn.)

8 Motor Challenge: replacing an oversized and underloaded electric motor. Fact sheet DOE/GO-10096-287. http://www1.eere.emergy.gov/ manufacturing/tech_deployment/pdfs/mc-2463.pdf

9 Bortoni, E.: 'Are my motors oversized?', Energy Convers. Manage., 2009, 50, pp. 2282-2287

10 McCoy, G.A., Litman, T., Douglass, J.G.: 'Energy-efficient electric motor selection handbook' (United States Department of Energy, Washington, 1993)

11 Energy Efficiency Guide for Industry in Asia: electric motors (training session on energy equipment, 2006). Available at http://www. energyefficiencyasia.org/energyequipment/ee_es_electricalmotors.html

12 MEEUP Methodology Report, Final. VHK for European Commission, 2005. http://ec.europa.eu/energy/demand/legislation/doc/2005_11_28_ finalreport1_en.pdf

13 Andrada, P., Blanqué, B., Martínez, E., Perat, J.I., Sánchez, J.A., Torrent, M.: 'Comparison of environmental and life cycle impact of a switched reluctance motor drive and inverter-fed induction motor drives'. Int. Conf. on Renewable Energies and Power Quality, ICREPQ'09, Valencia, 15-17 April 2009

14 Waide, P., Brunner, C.U.: 'Energy-efficient policy opportunities for electric motor-driven systems' (International Energy Agency, 2011)

$15 \mathrm{http}$ //epp.eurostat.ec.europa.eu/portal/page/portal/eurostat/home/ 